2013-9

\title{
Maximising Value of Electrical Networks for Wave Energy Converter Arrays
}

\author{
Fergus Sharkey \\ Technological University Dublin, fergus.sharkey@gmail.com \\ Elva Bannon \\ Wavebob Ltd. \\ Michael Conlon \\ Technological University Dublin, michael.conlon@tudublin.ie
}

See next page for additional authors

Follow this and additional works at: https://arrow.tudublin.ie/engscheleart2

Part of the Electrical and Electronics Commons, and the Power and Energy Commons

\section{Recommended Citation}

Sharkey, F., Bannon, E., Conlon, M. and Gaughan, K.Maximising Value of Electrical Networks for Wave Energy Converter Arrays. International Journal of Marine Energy, Volume 1, April 2013, Pages 55-69, ISSN 2214-1669, http://dx.doi.org/10.1016/j.ijome.2013.06.002

This Article is brought to you for free and open access by the School of Electrical and Electronic Engineering at ARROW@TU Dublin. It has been accepted for inclusion in Articles by an authorized administrator of ARROW@TU Dublin. For more information, please contact arrow.admin@tudublin.ie, aisling.coyne@tudublin.ie, gerard.connolly@tudublin.ie.

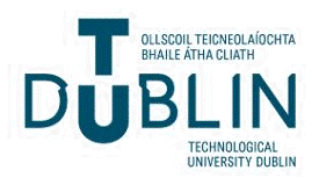




\section{Authors}

Fergus Sharkey, Elva Bannon, Michael Conlon, and Kevin Gaughan 


\title{
Maximising Value of Electrical Networks for Wave Energy Converter Arrays
}

\author{
Fergus Sharkey ${ }^{*}$, Elva Bannon ${ }^{\$ \$ 2}$, Michael Conlon ${ }^{\# 3}$, Kevin Gaughan ${ }^{\# 4}$ \\ ${ }^{\#}$ Dublin Institute of Technology, Kevin Street, Dublin 8, Ireland \\ ${ }^{*}$ ESB International, Stephens Green, Dublin 2, Ireland \\ ${ }^{1}$ fergus.sharkey@esbi.ie \\ ${ }^{3}$ michael.conlon@dit.ie, ${ }^{4}$ kevin.gaughan@dit.ie \\ ${ }^{\S}$ Wavebob Ltd, Maynooth, Co. Kildare, Ireland \\ ${ }^{\$}$ now of AWS Ocean Ltd, 12-14 Seafield Rd., Inverness, IV1 1SG, UK \\ 2elva.bannon@wavebob.com
}

\begin{abstract}
Currently there are the beginnings of a commercial wave energy industry and the ultimate ambition will be to deploy Wave Energy Converters (WECs) in arrays, or wave farms, in a similar fashion to offshore wind. These arrays will require electrical networks to collect and export the generated electrical power to shore and onto the electrical grid. For large scale wind farms the inter-array and export electrical networks can represent more than $20 \%$ of the project's capital expenditure. Submarine power cables account for a large proportion of this cost. The same is expected to be the same for WEC arrays.
\end{abstract}

This paper investigates strategies to reduce the cost of WEC array electrical networks by maximising the value of the network. The paper explores the possibility of underrating and dynamically rating the electrical array and export cable systems for WEC arrays in order to assess the cost savings that can be made. This paper will also look at a simulated WEC array power output time series. The aim is to establish whether the electrical equipment, particularly submarine cables, will operate outside its design parameters if under-rated based on maximum continuous current. This paper also investigates the WEC capacity factor effect on the overall economics of the array electrical system.

It is concluded that cost savings could be made in the electrical network by utilising one, or a combination of, the outlined strategies. Understanding the potential benefits and applications of these strategies will assist in delivering cost effective WEC arrays in the future.

Keywords: Wave Energy Converter, Electrical Network, Array, Submarine Cable, Dynamic Rating, Capacity Factor.

Abbreviations:

WEC:

Capex:

Wave Energy Converter

XLPE:

Capital Expenditure

CSA:

Cross Linked Polyethylene

RTTR:

Cross Sectional Area

DTS:

Real Time Thermal Rating

Distributed Temperature Sensing

\section{Introduction}

\subsection{WEC Array Electrical Networks}

The authors have previously outlined the electrical network configuration of small, medium and large WEC arrays [1]. This is based on the state of the art in offshore wind farm configurations and the array requirements of WECs. The electrical networks in these cases were designed and rated for the peak generation of all WECs, i.e. $100 \%$ rated current, and also using the cable manufacturers' current carrying capacity which are based on certain assumptions including ambient temperature, burial depth, and soil conditions, which are detailed in later sections. 
The design methodology and assumptions used are the conventional means of designing and rating an electrical network. However there are several strategies that may be employed which could improve the economics of the WEC array electrical network without adversely affecting the performance.

If one envisages an operating WEC array with multiple WECs connected in an electrical network such as that shown in Fig. 1 one could assume that all of the WECs will not be generating $100 \%$ output all of the time. Therefore, if the system is rated for $100 \%$ output it is under-utilised for some of the time, i.e. the system has a low utilisation factor. This paper explores the economic effect of under-rating (in the conventional sense) some of the electrical network to increase utilisation. This can be done simply by looking at the statistical output of a WEC array, detailed design based on environmental data, or by employing more sophisticated real-time monitoring systems to optimise the usage of the electrical network.

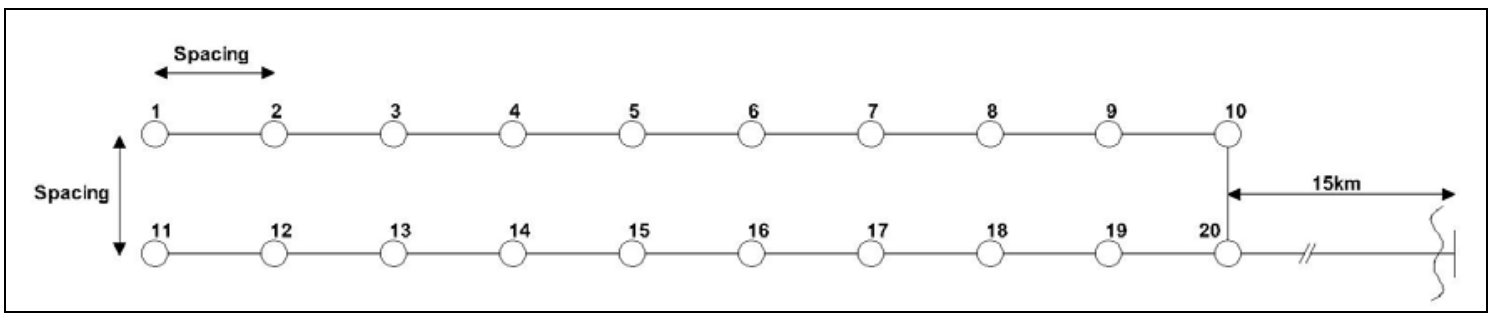

Fig. 1 - Electrical Network Layout of a WEC array

The initial electrical configurations in [1] also assumed a capacity factor of $30 \%$. The effect of a variety of WEC capacity factors on the electrical network economics is explored also.

The WEC array shown in Fig. 1 will be the candidate for analysis carried out in this paper. This was selected from [1] as it is a section of a 'medium' capacity WEC array. This WEC array is analysed for both $20 \mathrm{kV}$ and $33 \mathrm{kV}$ voltage ratings. Fig. 1 shows the electrical layout only and is not representative of the physical spatial arrangement, which may differ.

\subsection{Submarine Cable Cost Model}

Reliable costs must be established for the submarine cables in the network in order to objectively compare the economics of the electrical networks. Potential cost reductions in the electrical network capital expenditure (Capex) can then be quantified for different strategies. In the candidate WEC array (Fig. 1) no offshore substation is required so the large majority of electrical network costs are expected to come from the cable system.

The cost of submarine power cables is extremely volatile in that there are numerous factors that can affect the overall cost of the installed cable; namely materials cost (particularly copper and steel), mobilisation costs (significant for remote sites), seabed conditions (affecting installation method), downtime (determined by prevalent weather) and availability of equipment (determined by market demand). Therefore it is difficult to put a Euro price on cables that will remain relevant across all projects. Another approach is to look at the factors which make up the installed cost of a cable and develop a unitised, or normalised, cost model which will be valid with all else being equal in the cost of cables and installation methods across a particular project. This method disregards contract strategies such as bulk purchasing or multi-project which are not possible to model.

By looking at the elements of each factor of the cable cost a unitised cost model can be established. The main factors affecting the cable cost are;

1. The voltage rating of the cable (i.e. the insulation rating/thickness)

2. The cross sectional area (CSA) of the conductor

3. The installation costs

For simplicity we will assume 3 core Cross Linked Polyethylene (XLPE) cables with copper conductors and a single layer of armouring for all cases as these are common cables in the offshore wind industry. It should be noted that dynamic cables (i.e. the riser cable from the 
seabed to the WEC) would typically be designed with two layers of armour for torque balance; however this is not considered here.

As this is a unitised cost model a base case is required. The base case will be a $10 \mathrm{kV}$, $95 \mathrm{~mm}^{2}$ cable. This cable will have an installed unitised cost of 1.0 and all other cables will be represented as a multiple of this. The cost model was developed primarily using the formulae given by Lundberg in [2] and also verified by comparing against numerous sources such as [3]-[8]. The developed unitised costs are shown in Table 1 and also graphically in Fig. 2

For example a $33 \mathrm{kV}, 240 \mathrm{~mm}^{2}$ cable is $58 \%(1.58 / 1.0)$ more expensive than the base $10 \mathrm{kV}$, $95 \mathrm{~mm}^{2}$ cable. Also a $20 \mathrm{kV}, 500 \mathrm{~mm}^{2}$ cable is $165 \%(2.25 / 0.85)$ more expensive than a $20 \mathrm{kV}$, $50 \mathrm{~mm}^{2}$ cable.

\begin{tabular}{|c|c|c|c|c|}
\hline \multicolumn{5}{|c|}{ Installed Cable Unitised Costs } \\
\hline & \multicolumn{5}{|c|}{ Voltage } \\
\hline Cable CSA $\mathbf{( m m}^{2}$ ) & $\mathbf{1 0 k V}$ & $\mathbf{2 0 k V}$ & $\mathbf{3 3 k V}$ & $\mathbf{1 3 2 k V}$ \\
\hline 35 & 0.79 & 0.82 & 0.85 & - \\
\hline 50 & 0.81 & 0.85 & 0.88 & - \\
\hline 70 & 0.85 & 0.89 & 0.94 & - \\
\hline 95 & 1.00 & 1.05 & 1.11 & - \\
\hline 120 & 1.05 & 1.11 & 1.18 & - \\
\hline 150 & 1.10 & 1.17 & 1.25 & - \\
\hline 185 & 1.25 & 1.34 & 1.43 & - \\
\hline 240 & 1.35 & 1.46 & 1.58 & - \\
\hline 300 & 1.65 & 1.80 & 1.97 & - \\
\hline 400 & 1.80 & 1.99 & 2.21 & 2.79 \\
\hline 500 & 2.00 & 2.25 & 2.53 & 3.25 \\
\hline 630 & 2.25 & 2.55 & 2.89 & 3.75 \\
\hline
\end{tabular}

Table 1 - Unitised Submarine Cable Costs

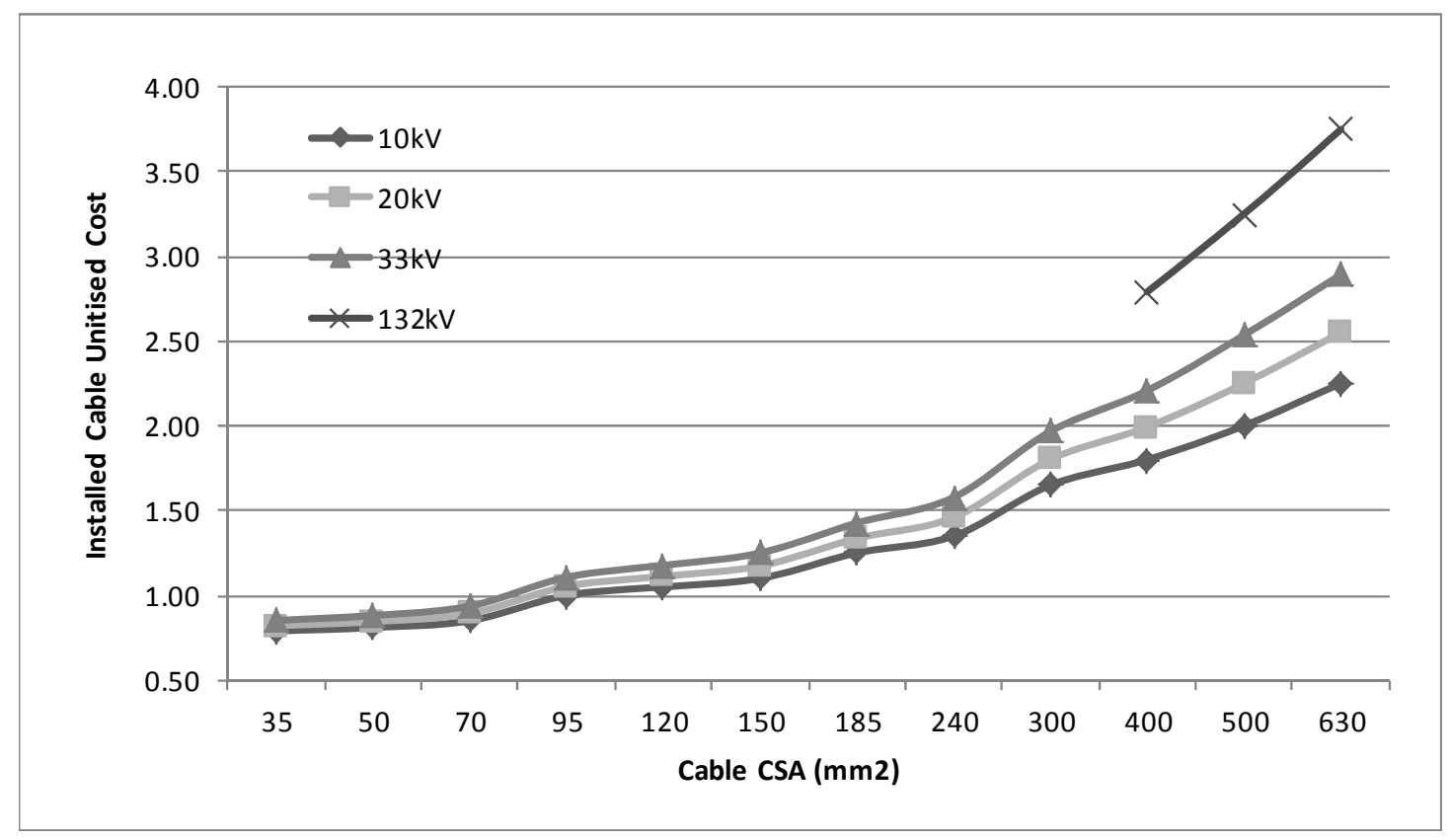

Fig. 2 - Installed Cable Unitised Costs

2. Maximising Value from WEC Array Electrical Networks

The purpose of this paper is to explore strategies to reduce the Capex of the electrical network of WEC arrays, i.e. to maximise the value of the electrical network asset with particular emphasis on the cabling system. This in turn will reduce the overall Capex of WEC arrays and help to make the business case for these more attractive. 
There are a number of strategies which are explored here in order to achieve this increase in the value from the WEC array electrical network. These will be analysed in detail in Section 3 but a brief description is given below. In some cases comparison is made to offshore wind to provide context, however it should be noted that WEC devices have very different characteristics than offshore wind turbines.

\subsection{Increased Capacity Factor}

The capacity factor of offshore wind turbines is typically in the region of 30-40\% [9] depending on turbine type, location, yearly wind speed etc. Another way of stating this is that offshore wind has a peak-to-average ration of $\sim 3: 1$. WEC characteristics are very different than wind turbines and there is far less convergence in WEC designs so each WEC may have a very different peak-to-average ratio on the same site. WECs must deal with a resource with a very high peak-to-average ratio and therefore without significant smoothing of captured power the output power may also have a very high peak-to-average ratio, i.e. a low capacity factor. So for example if a WEC has a rating of $1 \mathrm{MW}$ and a capacity factor of $30 \%$, then the average annual output for the WEC would be $300 \mathrm{~kW}$. If the same WEC had the same average annual output, but a capacity factor of $10 \%$, then the WEC would have a peak rating of $3 \mathrm{MW}$. This would obviously have an impact on the WEC array electrical network as the cables would need to be rated for the peak power. Larger, more expensive cables would be required even though the annual delivered energy (MWhrs) would not change. The opposite is also true in that a higher capacity factor would allow for smaller cables to be installed, thus reducing the electrical system costs.

The typical proportion of offshore wind farm Capex spent on electrical infrastructure is 20$25 \%$ [10] and this is expected to be similar for wave energy [11]. Therefore, designing a device with a high capacity factor will lend to a more cost effective electrical network.

Low capacity factor also suggests, although does not guarantee, a highly variable power output. This may have effects on power quality and grid compliance but is not the topic of study here.

\subsection{Less Than 100\% Rating Based on Statistical Data}

As outlined above it could be assumed that a WEC Array would rarely reach $100 \%$ output. This leads to the hypothesis that the electrical export system could be rated at less than $100 \%$ of 'nameplate' rating. In this case the rating will mean that the cable is under-rated when the WECs do reach maximum output simultaneously, leading to either output curtailment or a combination of one of the techniques described in Section 2.3 and 2.4 below. However any loss in energy may be offset by the initial savings gained from using a lower rated cable.

The UK National Grid \& Crown Estate established the optimum economic case for electrical export systems for offshore wind farms in [12]. This concluded that the optimum wind farm capacity was $112 \%$ of the export cable capacity or, in other words, the optimum export cable capacity was $89.3 \%$ of the wind farm capacity. This was based on the optimum MWhr/£GB Capex, taking into account availability and overall lifetime economics of the wind farm. The report acknowledged that curtailment of generation would be necessary at certain times. The same certainly may not hold true for WEC arrays with very different characteristics but it demonstrates the viability of exploring the concept for wave energy.

By simulating a small WEC array the effect that $<100 \%$ rating of the cabling has on the proportion of time that the cable limits are exceeded can be evaluated. From this the effect on the annual energy yield of the array can be established and it can be seen whether this is offset by the savings in the Capex of the electrical network.

\subsection{Dynamic Rating Based on Environmental Data}

The current carrying capacity, or ampacity, of power cables is calculated according to IEC60287 [13]. The maximum permissible continuous current is based on the maximum 
conductor operating temperature as defined by the cable manufacturer. For XLPE insulated cables this temperature is typically $90^{\circ} \mathrm{C}$ but can be lower. The cable must dissipate heat during normal operation so the maximum permissible current is calculated based on the thermal properties of all of the components of the cable (insulation, screens, sheaths, filler, armour, and serving), the cable geometry and the thermal properties of the surroundings.

The current ratings given in submarine cable specifications such as [14] use assumed values for the ambient conditions and surroundings such as those given below;

- Ambient temperature of $20^{\circ} \mathrm{C}$

- Sheaths bonded at both ends and earthed

- Burial depth of 1 metre

- Thermal resistivity of surroundings of $1 \mathrm{Km} / \mathrm{W}$

The ambient temperature, burial depth and thermal resistivity of the surroundings are somewhat within the control of the designer. These vary over time and over the length of the cable route. Therefore the maximum permissible current will vary also over time and across the route.

\subsection{Dynamic Rating Based on Real-Time Measurement}

Dynamic or Real Time Thermal Rating (RTTR) systems have been developed in order to utilise the 'headroom' available in transmission assets to increase the capacity at a given location. These systems monitor the environmental conditions (such as temperature, humidity etc.) and/or measure/model the temperature of the conductors themselves to allow dynamic constraints to be set on the system. This has been shown to allow $10-30 \%$ increased capacity over the static thermal rating of overhead lines [15].

To date this has been utilised successfully, with varying levels of sophistication, on transmission systems in a number of countries. It has also been utilised for offshore wind farm export cables [16].

These measurement technologies ensure that an accurate figure of the cable ampacity is maintained at all times thus allowing the cable asset to be utilised to its actual full permissible rating when required. Similar to the above methodology in Section 2.3, this would give greater accuracy and confidence regarding the actual maximum current rating at any given time.

\subsection{Other Methods}

Other methods which could potentially be employed include gas or liquid cooling, and burial methods (such as backfilling with low thermal resistivity aggregate) among others but these are considered outside the scope of this study as they are expected to be cost prohibitive.

Also of note is the study in [8] which looks at the 'sharing' of an export cable between an offshore wind farm and a WEC array. This is a novel idea and is shown to be advantageous in [8], however it is not explored further here.

\section{Detailed Analysis and Results}

Below is the detailed analysis performed for the four strategies presented in 2.1 to 2.4 . The method used is outlined in each section and the analysis is performed on the candidate WEC array, Fig. 1, with the exception of 3.2 which uses a 5 device array to reduce the complexity of the calculations.

\subsection{Increased Capacity Factor}

In order to investigate the economic effect that capacity factor has on the electrical network a base case is established with a rating of 1MVA per WEC and $30 \%$ capacity factor giving $300 \mathrm{kVA}$ annual average per WEC. If we maintain this annual average and vary the capacity factor from $10-60 \%$ we get the parameters for the study as shown in Table 2. 


\begin{tabular}{|c|c|}
\hline Capacity Factor & Device Rating \\
\hline $10 \%$ & $3 \mathrm{MVA}$ \\
\hline $20 \%$ & $1.5 \mathrm{MVA}$ \\
\hline $\mathbf{3 0 \%}$ (base case) & 1MVA \\
\hline $40 \%$ & $0.75 \mathrm{MVA}$ \\
\hline $50 \%$ & $0.6 \mathrm{MVA}$ \\
\hline $60 \%$ & $0.5 \mathrm{MVA}$ \\
\hline
\end{tabular}

Table 2 - Parameters for Capacity Factor Analysis

Naturally this means that the electrical system rating must be increased when the capacity factor falls and decreased when the capacity factor rises from the base case. For each of the capacity factors above the electrical system of the candidate WEC array (Fig. 1) is rated based on the maximum current. The overall cost of the electrical network is then calculated using the unitised submarine cost model introduced in Section 1.2. The resultant, relative costs are shown in Fig. 3 as multiples of the base case.

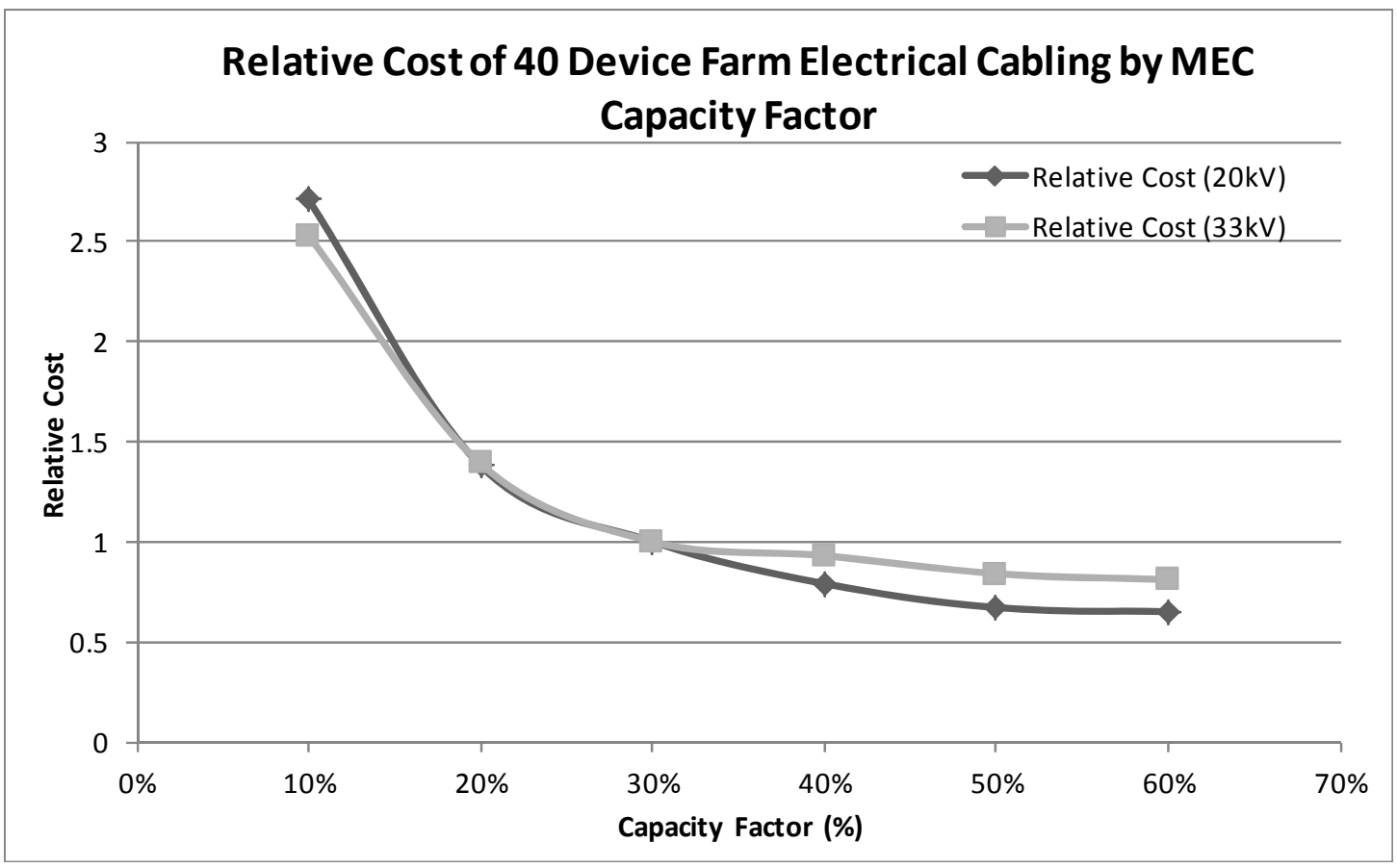

Fig. 3 - Relative Cost of Electrical Cabling versus WEC Capacity Factor

It can be seen that there is a significant cost penalty in reducing the capacity factor. Halving the capacity factor from $30 \%$ to $15 \%$ doubles the electrical network cost, but the benefits do not increase proportionally as the capacity factor is increased, i.e. doubling the capacity factor from $30 \%$ to $60 \%$ decreases the costs by $20-40 \%$.

This also shows that decreasing the capacity factor from $30 \%$ to $20 \%$ increases the electrical network cost by approx $40 \%$. Below a capacity factor of $20 \%$ the costs increase significantly.

Between $20 \%$ and $60 \%$ capacity factor there is approximately $\pm 40 \%$ variation in electrical system costs versus the base case of $30 \%$ capacity factor. There is a significant economic penalty from having a capacity factor of less than $20 \%$.

We can conclude that there are savings to be made in the electrical network Capex by increasing the capacity factor. We can also conclude that devices with capacity factors less than $20 \%$ will incur significant cost increases in the electrical network in comparison with devices with higher capacity factors, although this may be offset by some of the other strategies outlined here. From an electrical network perspective, device developers should aim to design for higher capacity factors. 


\subsection{Less Than 100\% Rating Based on Statistical Data}

A small WEC array is examined to assess the possibility of lowering the rating of some of the cables thus realising cost savings. For simplicity a 5-WEC array is considered here. It should be noted that this is a much simplified, idealised model of the system which is intended to demonstrate the principle only. It is noted that each WEC will have a different characteristic and the potential for this solution must be evaluated on a case by case basis

Unlike the candidate WEC array (Fig. 1), the physical spatial arrangement of the devices is considered here (Fig. 5). All WECs are considered identical and interference between WECs, either destructive or constructive, is not taken into account. Interference is an area of significant interest to the wave energy industry; however it is not considered to be sufficiently developed to be included in this study.

Since interference is not considered, if all 5 WECs are in a row which runs parallel to the approaching wavefront they would all react identically and simultaneously. If each individual WEC is generating $100 \%$ output then the WEC array is also generating $100 \%$ output.

A JONSWAP wave spectrum is used to generate an irregular wave elevation time series. This is fed into the Point Absorber WEC time domain model, derived from the time domain model in [17], which in turn gives a captured mechanical power time series for each WEC. In order to convert this captured mechanical power to an output electrical power the power-take-off (PTO) is simulated; first introducing a storage element by continuously averaging the captured mechanical power over half a wave period (i.e. $T_{\mathrm{p}} / 2$ ) and then allowing an assumed (conservative) $70 \%$ conversion efficiency. The output is then saturated to a maximum of 1MVA per device. This model is shown graphically in Fig. 4. Note again that this simplified model is used to demonstrate the principle only and is not representative of any particular WEC device.

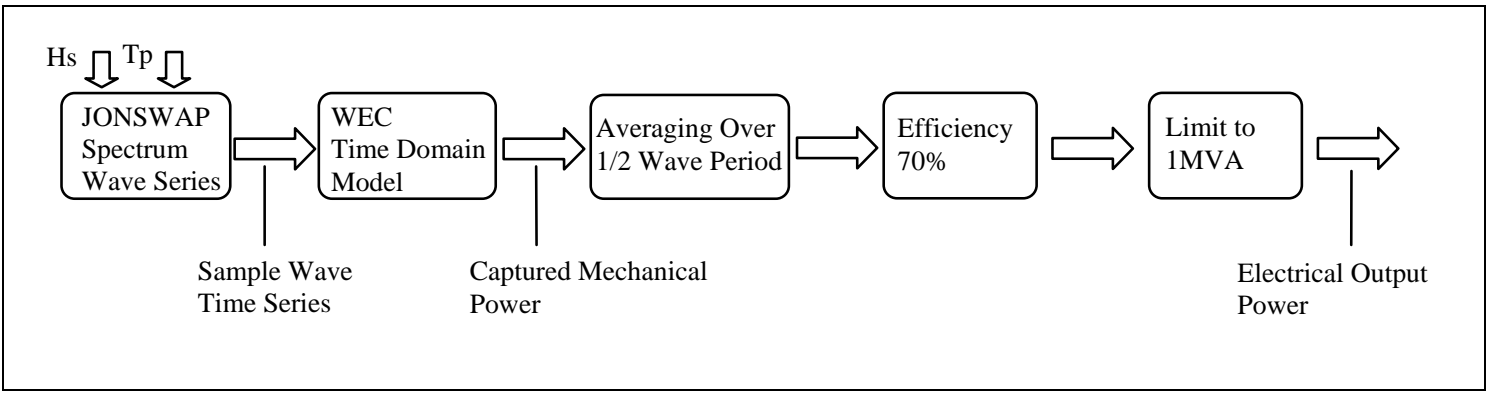

Fig. 4 - Representation of WEC and PTO Model for Analysis of Array Output

For simplicity, a 2D long crested irregular wave is considered incident on the array. In order to avoid simultaneous operation the array layout is staggered so that some devices will be out of phase with others regardless of the angle of incidence. This means that the 5 WECs may not react simultaneously to the oncoming wavefront, although there may be a combination of wave period and approach angle that allows this to occur. In a real seastate, short-crested waves would provide additional smoothing, so the case considered here may provide slightly more instantaneous peaks than in a more realistic seastate. This array is shown in Fig. 5 


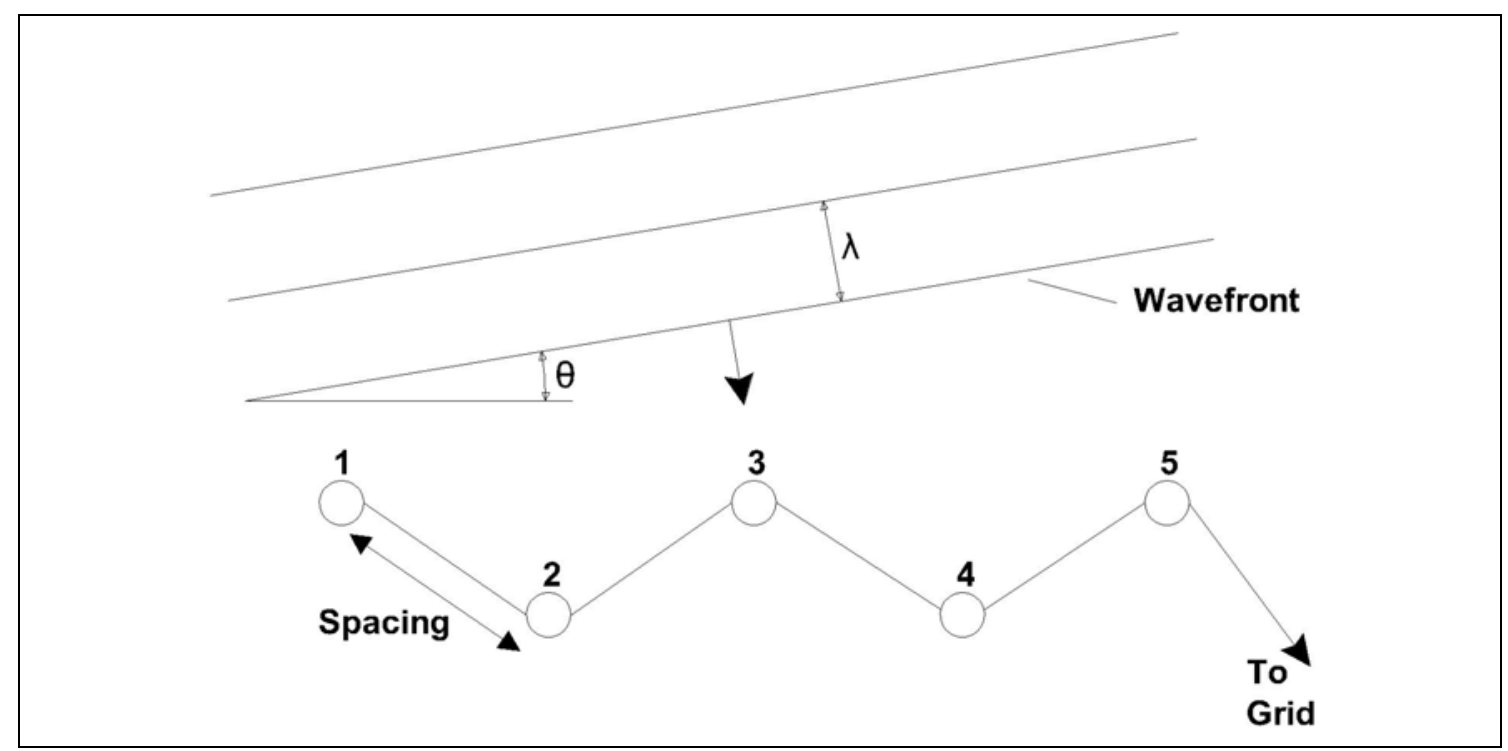

Fig. 5 - Concept of Array for Analysis ( $\theta=$ angle of incidence, $\lambda=$ wavelength)

The base case is established by sizing the cables in the array based on nameplate $(100 \%)$ output current. This assumes each WEC having a 1MVA rating. The electrical network will be at $10 \mathrm{kV}$ in this case as a higher voltage would not be necessary due to this array capacity. The cable cross sectional areas (CSA) required are shown below in Table 3 .

\begin{tabular}{|l|l|l|l|}
\hline Cable Link & $\begin{array}{l}\text { Required } \\
\text { Capacity }\end{array}$ & Rated Capacity & CSA \\
\hline 1-2 (400m) & 1MVA & $2.9 \mathrm{MVA}$ & $35 \mathrm{~mm}^{2}$ \\
\hline $2-3(400 \mathrm{~m})$ & 2MVA & $2.9 \mathrm{MVA}$ & $35 \mathrm{~mm}^{2}$ \\
\hline $3-4(400 \mathrm{~m})$ & 3MVA & $3.4 \mathrm{MVA}$ & $50 \mathrm{~mm}^{2}$ \\
\hline $4-5(400 \mathrm{~m})$ & $4 \mathrm{MVA}$ & $4.15 \mathrm{MVA}$ & $70 \mathrm{~mm}^{2}$ \\
\hline $\begin{array}{l}5-G r i d \\
(10 \mathrm{~km})\end{array}$ & $5 \mathrm{MVA}$ & $5 \mathrm{MVA}$ & $95 \mathrm{~mm}^{2}$ \\
\hline
\end{tabular}
Table 3 - Cable CSA for array based on maximum continuous current

It should be noted that this configuration gives large active power losses at $100 \%$ output, which would be unacceptable, however losses are ignored here as they do not dictate the cable CSA selection in larger arrays at higher voltage.

Focussing on the export cable only (i.e. WEC 5-Grid), reducing the cable CSA from $95 \mathrm{~mm}^{2}$ to $70 \mathrm{~mm}^{2}$ would reduce the export capacity from 5MVA to $4.15 \mathrm{MVA}$ or $83 \%$ of the rated array output. From the unitised cost model in Section 1.2 this will give a saving of $15 \%$ for the export cable. The time series output from the five devices is assessed to see if or when the overall output exceeds 4.15MVA. This will allow a cost benefit analysis to be carried out to see if the potential savings outweigh the possible loss of annual energy from the array.

A model of the array was built in MatLab $®$ which incorporates the power conversion shown in Fig. 4 for each WEC. The angle of incidence of the approaching wavefront can be varied to give the total output of the five devices for any sea state and any angle of incidence. This model is shown graphically in Fig. 5 . Spacing is $400 \mathrm{~m}$ between WECs. The combined output of all of the devices in the array gives the output power across the export cable (WEC 5-Grid). As mentioned previously losses are not considered here.

If the angle of incidence is $0^{\circ}$ the wavefront is parallel to the line dissecting WECs $1,3 \& 5$. Therefore, the wavefront will meet these three WECs simultaneously and also WECs 2 \& 4 simultaneously though out of phase with WECs $1,3 \& 5$. This would be considered the worst case scenario, and this was confirmed by analysing the output of the array between $0^{\circ}$ and $90^{\circ}$ angle of incidence. In all cases the worst case output, i.e. the output with the highest occurrence of array peak power was given at $0^{\circ}$. 
The proportion of time that the array generates maximum output (5MVA), and the proportion of time the array generated more than $83 \%$ output (>4.15MVA) were evaluated for all seastates (i.e. all combinations of $\mathrm{Hs}$ and $\mathrm{Tp}$ in the scatter diagram). These proportions were multiplied by the percentage occurrence of these cells from the Belmullet (West Mayo, Ireland) scatter diagram, as shown in Fig. 6, to give the annual proportion for each value. The percentage of energy generated during the period where the array output was greater than 4.15MW was also calculated. These values were all taken at $0^{\circ}$ angle of incidence. Results are shown in Table 4.

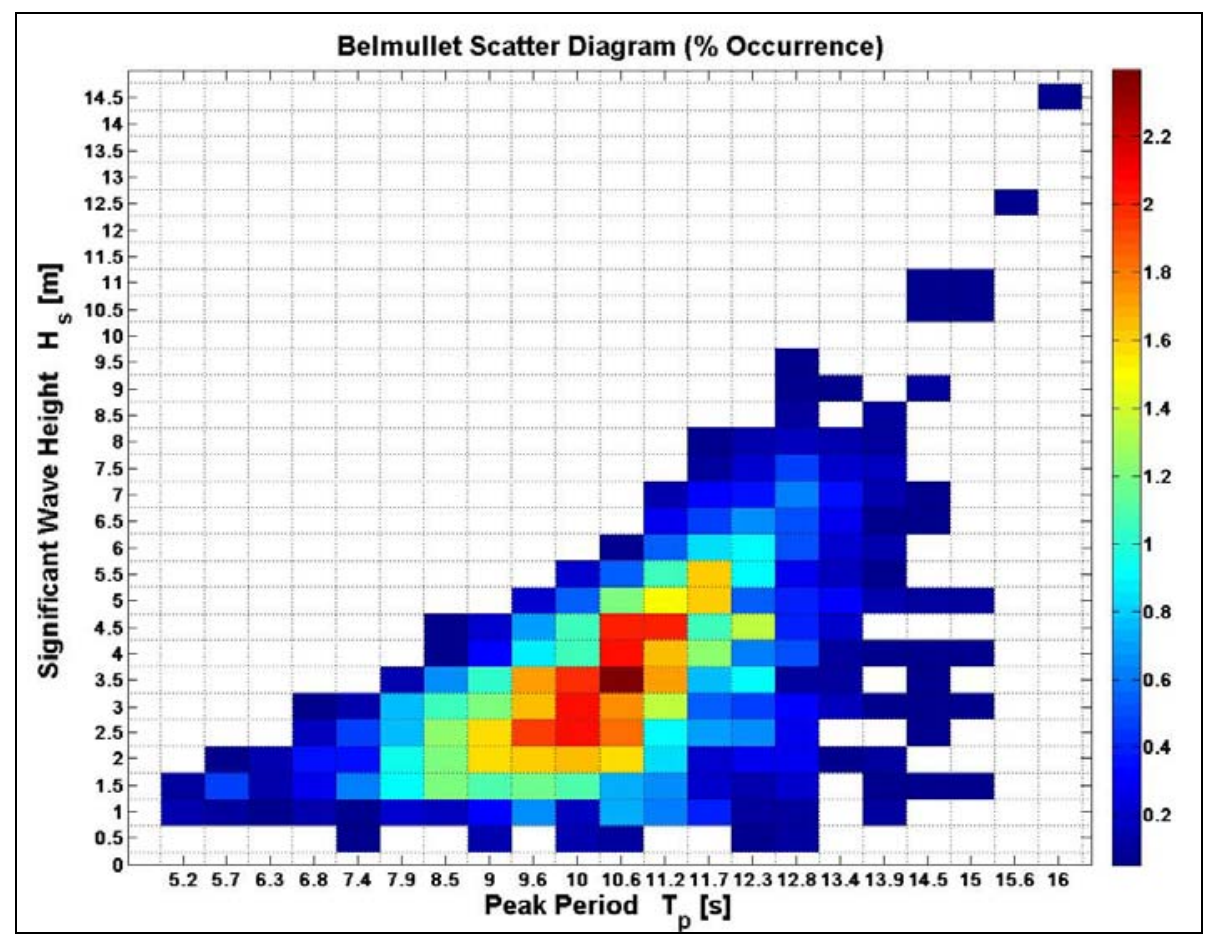

Fig. 6 - Belmullet Scatter Diagram [18]

\begin{tabular}{|l|c|c|}
\hline & $\begin{array}{l}\text { 100\% Output } \\
\text { (5MVA) }\end{array}$ & $\begin{array}{l}\text { >83\% Output } \\
\text { (>4.15MVA) }\end{array}$ \\
\hline $\begin{array}{l}\text { Total Annual } \\
\text { Output (Time) }\end{array}$ & $3.20 \%$ & $6.20 \%$ \\
\hline $\begin{array}{l}\text { Total Annual } \\
\text { Energy (MWhrs) }\end{array}$ & N/A & $2.98 \%$ \\
\hline
\end{tabular}

Table 4 - Annual output Occurrence and annual energy output proportion for analysed data

It can be seen that in the course of a year the output power of the full array is $100 \%$ (5MVA) for $3.2 \%$ of the total time and greater than $83 \%$ ( $>4.15 \mathrm{MVA}$ ) for $6.2 \%$ of the time.

However the energy supplied in the time that the array output is $>83 \%$ ( $>4.15 \mathrm{MVA}$ ) is only $2.98 \%$ of the total annual energy output. This means that if the cable was $70 \mathrm{~mm}^{2}$ instead of the $95 \mathrm{~mm}^{2}$ less than $3 \%$ of the overall energy (MWhrs) would need to be curtailed, i.e. would be lost.

To analyse the financial implications of this we would need to know the exact costs of the cable, the revenue expected and also the cost of capital. For the purpose of demonstration it is assumed that a $95 \mathrm{~mm}^{2}$ cable costs $€ 350 / \mathrm{m}$ installed and that the revenue for energy is $€ 200 / \mathrm{MWhr}$. Also a $10 \%$ cost of capital is assumed. The 'discounted years to break even' is defined as the time in which the saved Capex, plus the potential interest on the saved Capex, will be offset by the lost revenue. This is a simple 'present value' annuity calculation solved for the number of payments (i.e. number of years) as shown in Equation 1 and can be repeated with the $=$ NPER() function in MS Excel. Table 5 shows the relevant calculated results. 


\begin{tabular}{|c|c|}
\hline $\begin{array}{l}\text { Annual energy (with } 30 \% \text { capacity } \\
\text { factor): }\end{array}$ & 13,140MWhrs \\
\hline Annual revenue no curtailment & $€ 2.628 \mathrm{~m}$ \\
\hline $\begin{array}{l}\text { Annual revenue with curtailment of } \\
2.98 \% \text { : }\end{array}$ & $€ 2.550 \mathrm{~m}$ \\
\hline $\begin{array}{llll}\text { Lost revenue per annum with } \\
\text { curtailment }\end{array}$ & $€ 78,314.40$ (D) \\
\hline Capex for $10 \mathrm{~km}$ of $95 \mathrm{~mm}^{2}$ cable & $€ 3.5 \mathrm{~m}$ \\
\hline $\begin{array}{l}\text { Capex for } 10 \mathrm{~km} \text { of } 70 \mathrm{~mm}^{2} \text { cable (- } \\
15 \%)\end{array}$ & $€ 2.975 \mathrm{~m}$ \\
\hline Savings from CSA reduction & $€ 525 \mathrm{k}(\mathrm{A})$ \\
\hline Cost of Capital & $10 \%(\mathrm{~B})$ \\
\hline Discounted years to break even & $\sim 10$ years $(C)$ \\
\hline
\end{tabular}

Table 5 - Hypothetical 'break-even' calculation

$$
A \times\left((1+B)^{C}+D(1+B) \times\left(\frac{(1+B)^{C}-1}{B}\right)\right)=0
$$

This hypothetical situation above shows that the initial savings in Capex gained from utilising a smaller cable will be offset within 10 years by the lost revenue. Over a typical 25 year project this would not make financial sense. This assumes $100 \%$ availability, high revenue which may fall over time, and neglects active power losses so in fact revenue will be lower.

It should be noted that the figures established above are based on $0^{\circ}$ angle of incidence, which is the worst case scenario and uses idealised wave conditions. In reality any given site will have a prevailing wave direction, and also a spread of angles for the incoming wave. To reduce the likelihood of devices reacting simultaneously to an oncoming wave, the WEC array could be orientated away from the prevailing wave direction. Therefore, the percentage annual energy $>4$.15MVA could be lowered.

Other techniques such as detuning individual WECs to change their response characteristic and further staggering of the array to increase the phase shifting between devices could also allow for further reductions in potential energy curtailment. As an example the row of WECs 1 , $3 \& 5$ were taken out of phase by putting a constant time delay of 2 seconds between WECs $1 \& 3$ and 4 seconds between WECs $1 \& 5$. In this case the energy curtailed for a $70 \mathrm{~mm}^{2}$ cable drops from $2.98 \%$ to $1.96 \%$. This leads to a 28 year 'discounted years to break even' in the hypothetical case shown above in Table 5 . Therefore, by staggering the array further the amount of energy to be curtailed can be reduced and the economics will become more favourable.

Using simplified models and a number of assumptions the principle of this strategy for cable system cost reduction shows promise However the conclusions here are only based on the much simplified model given in Figure 4 and the much simplified array given in Figure 5. With more reliable device and array modelling including interference, detailed cost benefit analysis based on expected revenues, availability data, confirmed cable costs and calculated cable losses a business case could be made to employ this methodology to the WEC array electrical system.

Also note that the ampacity ratings are taken from IEC 60287 , which is based on $100 \%$ load factor. Additional short term ampacity would be available in the cable by employing methods from IEC 60853, which looks at cyclic loading and emergency current ratings [19]. This may allow the cable to be utilised above its ampacity rating for short periods, thus reducing potential curtailment further still.

This strategy could also be combined with one of the strategies below which may reduce the amount of potential curtailment to a negligible level. 


\subsection{Dynamic Rating Based on Environmental Data}

As mentioned previously the ampacity of a cable is a function of its ability to dissipate heat. This is based on a number of factors some of which will vary both over time and across the route of the cable as it passes from one zone to another. These factors are based on environmental data such as seawater and air temperature and route conditions such as burial depth and seabed/soil conditions. These conditions can be accurately established from historical data and site measurements, allowing the setting of seasonal ratings and the calculation of accurate ampacity.

By focussing on our candidate WEC array (Fig. 1) and in particular the export cables which are $400 \mathrm{~mm}^{2}$ for $20 \mathrm{kV}$ and $150 \mathrm{~mm}^{2}$ for $33 \mathrm{kV}$, we can evaluate the effect of lowering the cable CSA. Table 6 shows the ampacity of these cables (and the next CSA down) at the assumed values (see Section 2.3).

\begin{tabular}{|c|c|c|c|}
\hline Voltage & $\begin{array}{l}\text { Required } \\
\text { Ampacity }\end{array}$ & Cable CSA & $\begin{array}{c}\text { Ampacity } \\
\text { (assumed } \\
\text { values) }\end{array}$ \\
\hline \multirow[t]{2}{*}{$20 \mathrm{kV}$} & \multirow[t]{2}{*}{$567 \mathrm{~A}$} & $400 \mathrm{~mm}^{2}$ & $627 \mathrm{~A}$ \\
\hline & & $\begin{array}{c}300 \mathrm{~mm}^{2} \\
\text { (next CSA } \\
\text { down) }\end{array}$ & $564 \mathrm{~A}$ \\
\hline \multirow[t]{2}{*}{$33 \mathrm{kV}$} & \multirow[t]{2}{*}{$347 \mathrm{~A}$} & $150 \mathrm{~mm}^{2}$ & $368 \mathrm{~A}$ \\
\hline & & $\begin{array}{c}120 \mathrm{~mm}^{2} \\
\text { (next CSA } \\
\text { down) }\end{array}$ & $330 \mathrm{~A}$ \\
\hline
\end{tabular}

Table 6 - Ampacity of Rated and Next CSA down for WEC Array

Focussing on the west coast of Ireland, Fig. 7 shows that the seawater temperature varies seasonally from approx $6-15^{\circ} \mathrm{C}$. Also the air temperature for the land based portion of the cable is important and this is shown in Fig. 8 and varies seasonally from approx $3-17^{\circ} \mathrm{C}$ although with some extremes. This implies that the cable ampacity will vary throughout the year due to ambient temperatures.

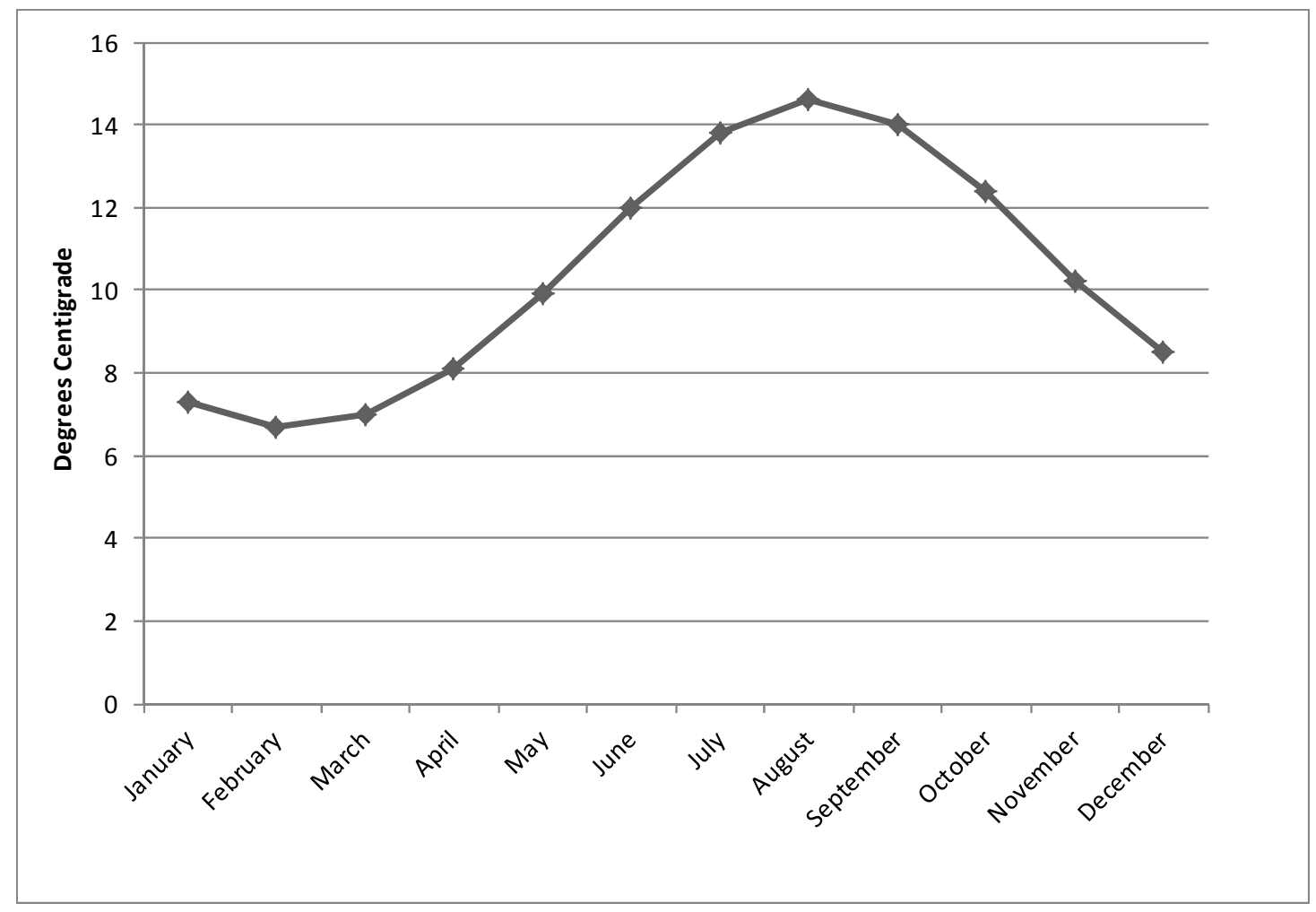


Fig. 7 - Average Monthly Seawater Temperature at Malin Head 1961-1990 (source: Met Eireann)

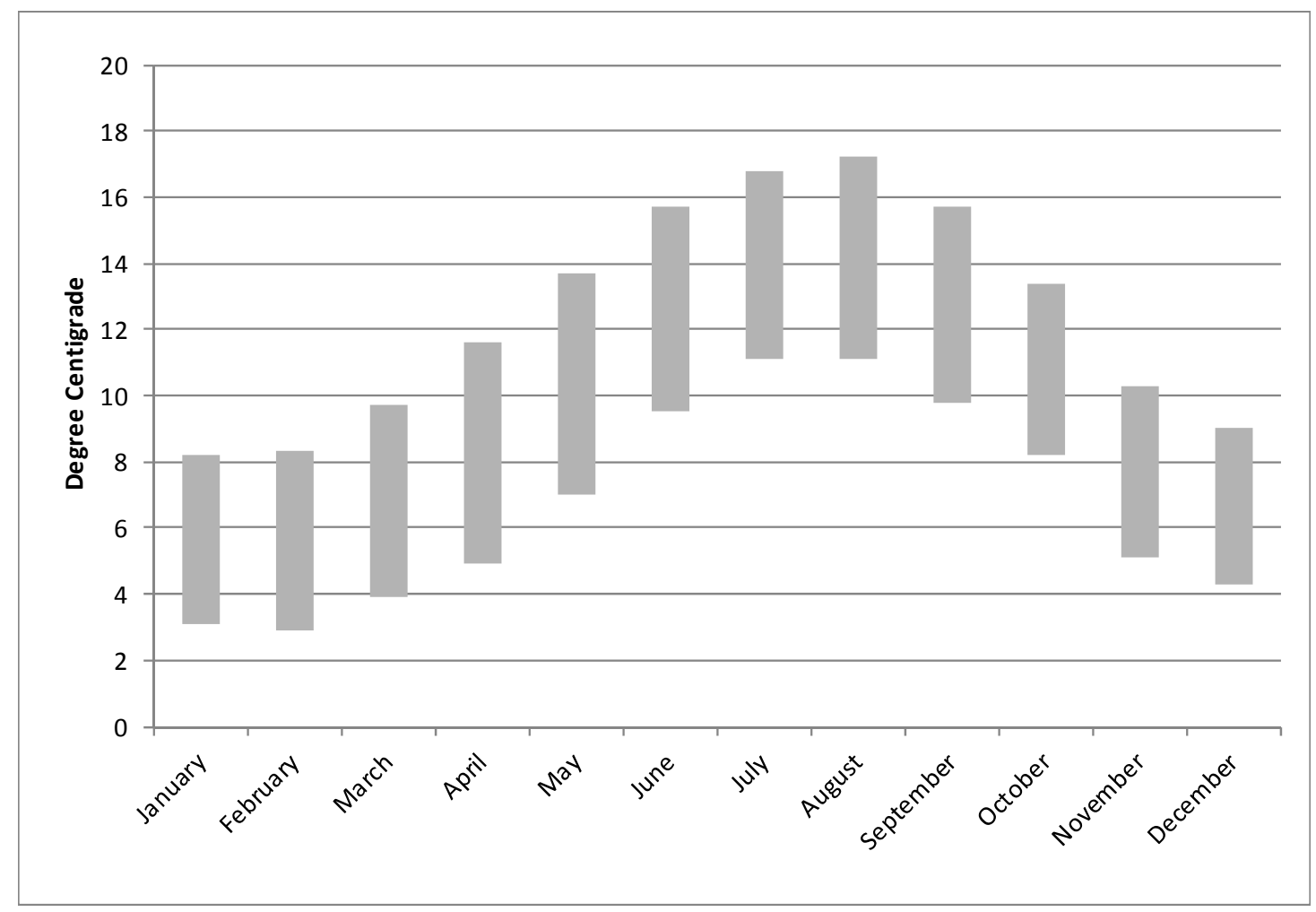

Fig. 8 - Average Monthly Air Temperature Range at Belmullet 1961-1990 (source: Met Eireann)

It is assumed for this analysis that the worst thermal resistivity along the route is $1.0 \mathrm{Km} / \mathrm{W}$ and that the burial depth is $1.0 \mathrm{~m}$ along the entire cable route. From this information we can show the available and required ampacity across the year for the selected cable and the next lowest size cable. The air temperature is used for the calculation as it has higher extremes than the seawater temperature and the land section of the submarine cable would be expected to be a "bottleneck" as a result.

Fig. 9 shows the results of the seasonal adjustment for a $20 \mathrm{kV}$ system. Based on the adjustment of the seasonal temperatures alone we can show that a $300 \mathrm{~mm}^{2}$ cable is more suitable for this application. The output of the array almost reaches the ampacity limit in the summer months; however this is only when the output of the array is $100 \%$. Thus by understanding the environmental data the cable size has decreased from that using the assumed values. 


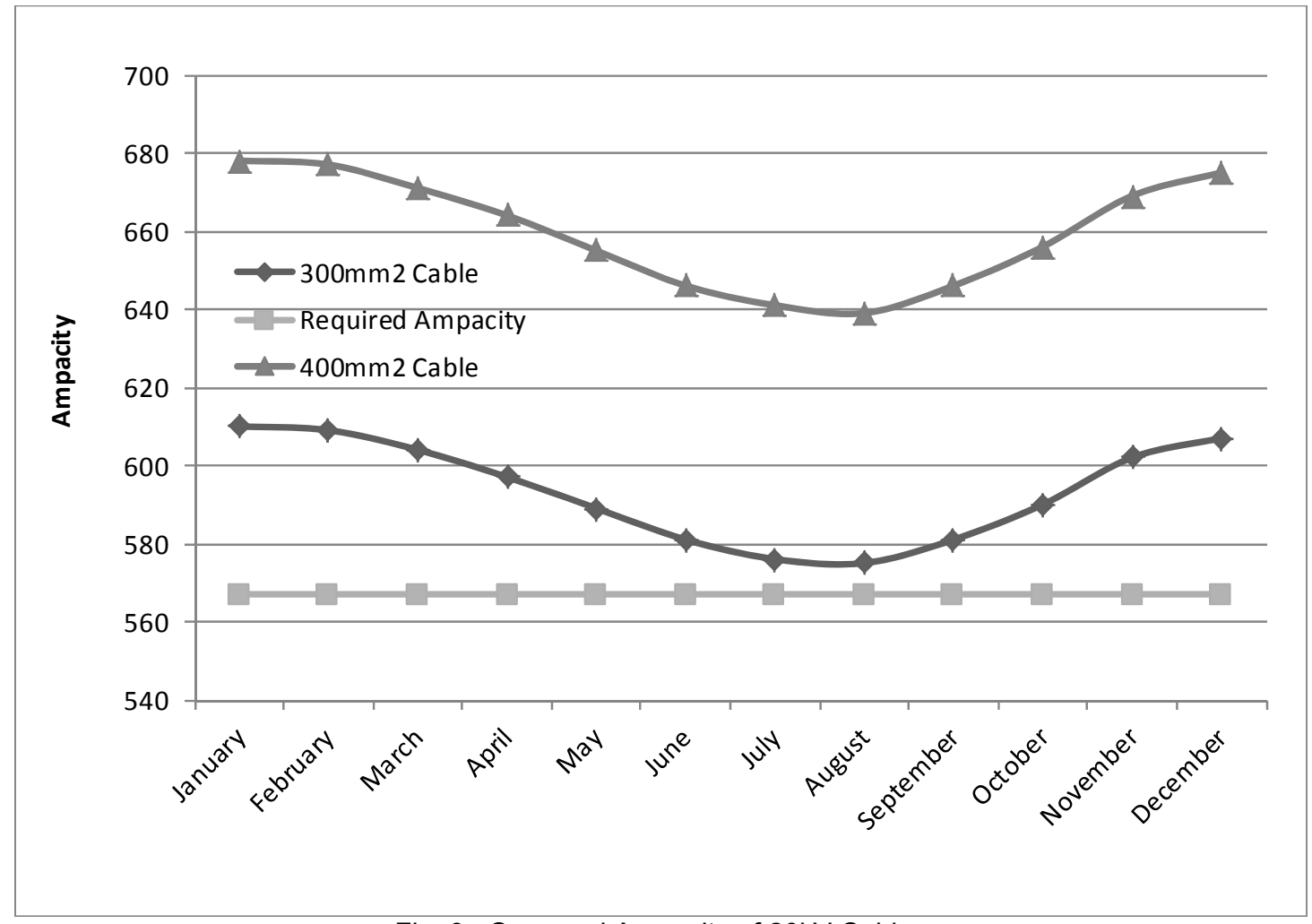

Fig. 9 - Seasonal Ampacity of 20kV Cables

Fig. 10 shows the results of the seasonal adjustment for a $33 \mathrm{kV}$ system. Based on the adjustment of the seasonal temperatures alone we can show that a $120 \mathrm{~mm}^{2}$ cable is not suitable for this application. The output of the array exceeds the ampacity limit of the $120 \mathrm{~mm}^{2}$ cable from May through October; however this is only when the output of the array is greater than $95 \%$. Thus from this analysis a $150 \mathrm{~mm}^{2}$ cable is more suitable. However, one of the other methods, such as that in Section 3.2 above may be applied to allow the use of a $120 \mathrm{~mm}^{2}$ cable. 


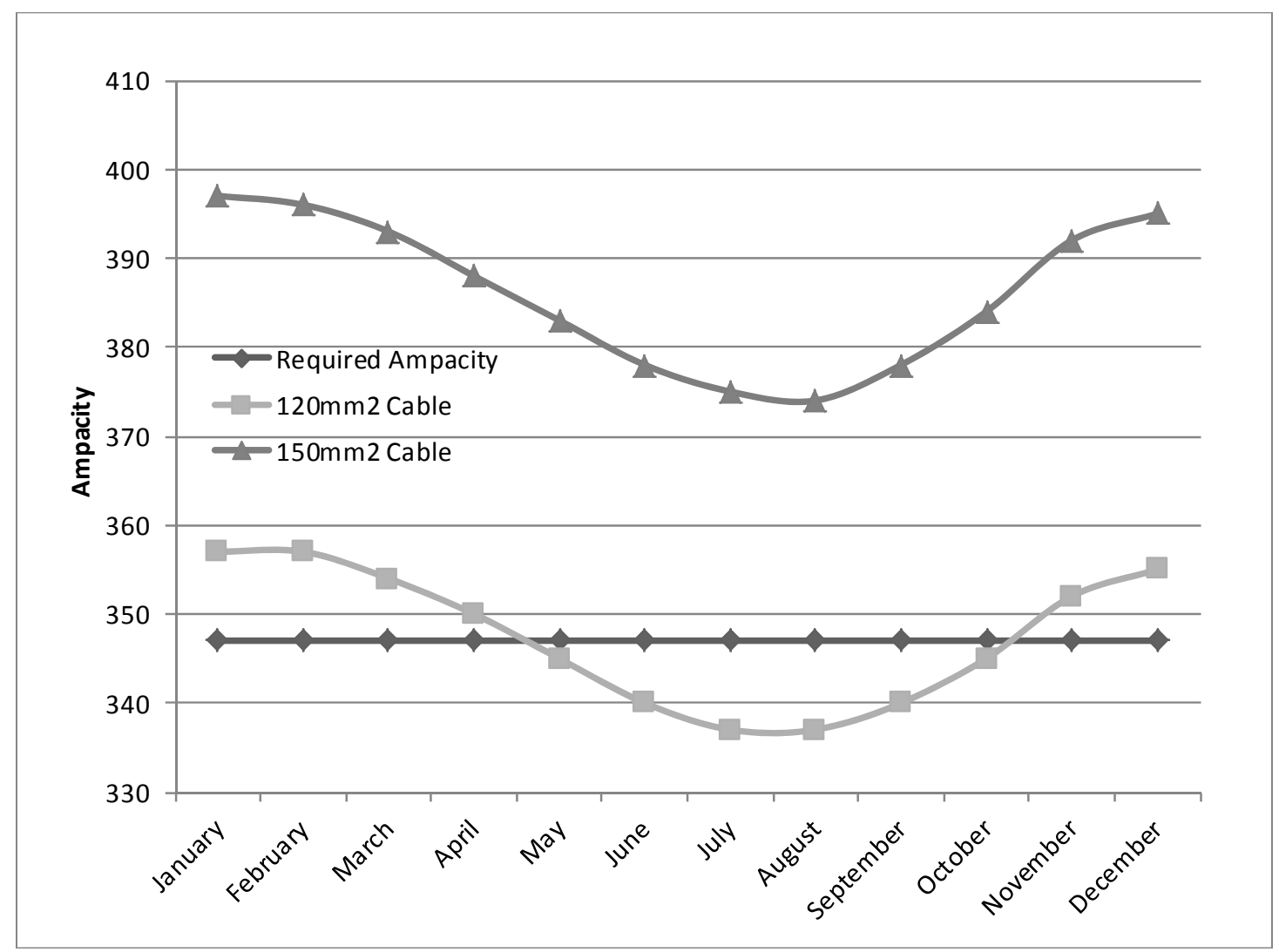

Fig. 10 - Seasonal Ampacity of 33kV Cables

For the $20 \mathrm{kV}$ array the reduction in cost of the export cable by reducing the cable from $400 \mathrm{~mm}^{2}$ to $300 \mathrm{~mm}^{2}$ would be approx $10 \%$. For the $33 \mathrm{kV}$ array the cost savings from reducing the export cable from $150 \mathrm{~mm}^{2}$ to $120 \mathrm{~mm}^{2}$ would be approx $6 \%$. These saving only consider the export cables. Further savings to the overall electrical system costs could be made by reducing the array cables CSA, particularly those nearest the export side, using the same method.

\subsection{Dynamic Rating Based on Real Time Measurement}

The methodology in Section 3.3 above carries a certain amount of risk as there may be times when the air temperature is significantly higher than the average for a given month. Therefore the system is normally designed for extremes to introduce a factor of safety.

In order to remove this risk real time measurement may be utilised to ensure that the ampacity of the cable is calculated in real time and the cable is never at risk of becoming overloaded. This can be done by simply measuring the ambient temperatures at several locations along the route and using a model of the cable to calculate ampacity. However this does not give actual real-time data about the conductor temperature and simply gives a calculated ampacity at a given time. More complex distributed temperature sensing (DTS) systems which measure the actual temperature of the conductor across the entire cable route will allow a very high degree of certainty in the loading at a given time.

DTS systems can use fibre optic technology which through a combination of back scattered light intensity and time domain reflectometry can measure the temperature to one metre resolutions in cables up to $30 \mathrm{~km}$ in length [16][20]. This can give a temperature profile of the entire length of the cable thus allowing accurate loading of the cable, i.e. accurate dynamic ampacity ratings, and identification of hotspots along the route. While the DTS fibre optic cable can be installed after cable manufacture, it is preferable to install the sensing cable during manufacture as this will improve response time and makes the system integral to the power cable. 
Such a real time system would allow the operator to use the strategies given in this paper with full confidence that the power cable asset will be maintained within safe limits. It also means that any output curtailment will be kept to an absolute minimum. Naturally such a system will increase the costs of the installation but this would be expected to be a marginal increase and offset with potential savings in the reduction of cable CSAs.

\section{Conclusions}

The costs of the electrical network for WEC arrays is expected to follow that of offshore wind farms with $20-25 \%$ of Capex required for the offshore and onshore electrical infrastructure [11]. A large portion of this expenditure will be on the submarine electrical network. If reduction in Capex can be made in this area a more solid business case can be made for commercial WEC arrays.

If wave energy converters with a capacity factor of approx $30 \%$ are installed in an array, the utilisation factor of the electrical network and in particular the export cable would also be $30 \%$. A number of strategies are proposed to increase the utilisation of the power cables for a WEC array which will ultimately mean a reduction in cost for the electrical network.

Increasing the capacity factor of the individual WECs will increase the utilisation factor and thus reduce the cost of the electrical network. Savings of up to $40 \%$ of the cost of the cable network could be expected. Conversely, if the WECs have a capacity factor of less than $20 \%$, the costs could be expected to rise significantly. The design of the WEC device itself will dictate the capacity factor, but device developers should note the economic penalties of a low capacity factor device within an array.

Modelling and simulation of an array of WECs can assist in providing statistical data of the WEC array power output. This permits the assessment of the utilisation of the electrical infrastructure and reduction in export cable capacity by $10-20 \%$ to allow reduction in costs of the electrical network. This may require some curtailment of the array output power but should be a very small percentage of annual energy from the WEC array. Strategic spacing of the WECs within the array may be required to achieve this effect but could be further optimised to reduce energy curtailment. This strategy coupled with other methods described here could potentially lead to no loss of energy whatsoever within the array while giving a saving in Capex.

The use of detailed environmental data from the site location could allow the ampacity of a cable to be modelled annually. This would allow the maximum utilisation of the cable at all times of the year and curtailment at times when the cable design limits may exceeded. Through this a reduction in export cable capacity by $10-20 \%$ may also be achieved thus also reducing Capex.

Real time distributed temperature sensing (DTS) will provide a constantly updating profile of temperature across the entire length of the cable. This will allow accurate and reliable dynamic ampacity of the cable to be calculated thus allowing the full utilisation of the cable at all times. It will also serve to identify hotspots along the cable route and protect the cable over the long term.

These strategies have been shown to allow for cost reductions and increased utilisation of the power cables. The choice of strategy will depend on the overall economics of the project and the information available to the designer while specifying the electrical system. It should be noted that the strategies listed above, although demonstrated on power cables, would also have applications in other power system components in the WEC array electrical network such as power transformers, power converters and switchgear.

\section{Acknowledgements}

The authors would like to acknowledge the contribution of the Wavebob team in providing models for use within this report. The authors would also like to acknowledge the members of the ESB International Ocean Energy department for their support of this work. 


\section{References}

[1] F. Sharkey, M. Conlon \& K. Gaughan. Investigation of Wave Farm Electrical Network Configurations. Proc. of World Renewable Energy Congress (WREC), Linkoping, Sweden, 2011.

[2] S. Lundberg. Performance Comparison of Wind Park Configurations. Chalmers University, Technical Report, 2003. Available at: http://publications.lib.chalmers.se/publication/2691-performance-comparison-of-wind-parkconfigurations - accessed December 2011

[3] J. Green, A. Bowen, L. Fingersh \& Y. Wan. Electrical Collection and Transmission Systems for Offshore Wind Power. Proc. of Offshore Technology Conference, Houston, Texas, 2007

[4] M. Kenny. Electrical Connection Issues for Wave Energy Arrays University College Cork, Masters Thesis, 2010. Available at: http://library.ucc.ie/record=b2047727 - accessed May 2013

[5] P. Djapic \& G. Strbac. Cost Benefit Methodology for Optimal Design of Offshore Transmission Systems. (Centre for) Sustainable Electricity and Distributed Generation - SEDG, Technical Report. 2008. Available at: http://www.sedg.ac.uk/Publication/Cost $\% 20$ Benefit $\% 20$ Methodology $\% 20$ for $\% 200$ ptimal\%20Design $\% 20$ of $\% 20$ Offshore\%20Transmission\%20Systems.pdf - accessed May 2013

[6] Department of Trade and Industry (DTI). Study of the Costs of Offshore Wind Generation. 2007. Available at: http://webarchive.nationalarchives.gov.uk/+/http://www.berr.gov.uk/files/file38125.pdf - accessed May 2013

[7] P. Hopewell, F. Castro-Sayas \& D. Bailey. Optimising the Design of Offshore Wind Farm Collection Networks. Proc. of $41^{\text {st }}$ Universities Power Engineering Conference. Vol 1 (2006) - pp 84-88

[8] E. Stoutenburg \& M Jacobson. Optimizing Offshore Transmission Links for Marine Renewable Energy Farms. Proc. of OCEANS 2010. (2010) pp 1-9

[9] N. Boccard. Capacity Factor of Wind Power Realized Values versus Estimates. Energy Policy vol. 37 (2009). pp. 2679-2688.

[10] R. Green, N. Vasilakos. The Economics of Offshore Wind. Energy Policy, vol. 39 (2010). pp. 496-502

[11] RenewableUK. Channeling the Energy- A Way Forward for the UK Wave \& Tidal Industry Towards 2020 October 2010. Available at: http://www.renewableuk.com/en/publications/index.cfm/Wave-and-TidalChannelling-the-Energy - accessed May 2013

[12] The Crown Estate (National Grid) - Round 3 Offshore Wind Farm Connection Study, Technical Report, 2010. Available at http://www.thecrownestate.co.uk/media/214799/round3 connection study.pdf - accessed May 2013

[13] IEC 60287 - Electrical Cables - Calculation of the Current Rating, Technical Standard.

[14] Nexans Ltd. Submarine Power Cables Specifications, Technical Brochure. Available at http://www.nexans.de/Germany/2010/NEX SubmPowCables mai08.pdf - accessed May 2013

[15] T Seppa. Increasing Transmission Capacity by Real Time Monitoring. Proc. of IEEE Power Engineering Society Winter Meeting. Vol 2 (2002), pp. 1208-1211.

[16] J. Downes \& H. Leung. Distributed temperature sensing worldwide power circuit monitoring applications. Proc. of International Conference on Power System Technology. Vol 2 (2004), pp 1804-1809.

[17] J. J. Cândido, and J. A. P. Justino, Frequency, stochastic and time domain models for an articulated wave power device, Proc. of the ASME 27th International Conference on Offshore Mechanics and Arctic Engineering (OMAE2008), 2008, paper OMAE2008-57253, pp. 633-643

[18] D. Mollison. Irelands Wave Power Resource - A Report to the National Board for Science and Technology and Electricity Supply Board. N.B.S.T, 1982

[19] IEC 60853. Calculation of the Cyclic and Emergency Current Ratings of Cables, Technical Standard

[20] M. Luton, G. Anders, J Braun, N. Fujimoto, S Rizzetto \& J. Downes. Real Time Monitoring of Power Cables by Fibre Optic Technologies Tests, Applications and Outlook. Proc. of International Conference on Insulated Power Cables. 2003 